\title{
Associations of Physical Activity and Sedentary Behaviour Assessed by Accelerometer with Body Composition among Children and Adolescents: A Scoping Review
}

\author{
Emanuela Gualdi-Russo ${ }^{1}$ (D), Natascia Rinaldo ${ }^{1, *}$, Stefania Toselli ${ }^{2, *(\mathbb{D})}$ and Luciana Zaccagni ${ }^{1,3}$ \\ 1 Department of Neuroscience and Rehabilitation, Faculty of Medicine, Pharmacy and Prevention, \\ University of Ferrara, 44121 Ferrara, Italy; emanuela.gualdi@unife.it (E.G.-R.); \\ luciana.zaccagni@unife.it (L.Z.) \\ 2 Department of Biomedical and Neuromotor Science, University of Bologna, 40126 Bologna, Italy \\ 3 Center of Sport and Exercise Sciences, University of Ferrara, 44123 Ferrara, Italy \\ * Correspondence: natascia.rinaldo@unife.it (N.R.); stefania.toselli@unibo.it (S.T.)
}

check for updates

Citation: Gualdi-Russo, E.; Rinaldo, N.; Toselli, S.; Zaccagni, L. Associations of Physical Activity and Sedentary Behaviour Assessed by Accelerometer with Body Composition among Children and Adolescents: A Scoping Review. Sustainability 2021, 13, 335. https://doi.org/10.3390/su13010335

Received: 2 December 2020 Accepted: 28 December 2020 Published: 31 December 2020

Publisher's Note: MDPI stays neutral with regard to jurisdictional clai$\mathrm{ms}$ in published maps and institutional affiliations.

Copyright: $(\odot 2020$ by the authors. Licensee MDPI, Basel, Switzerland. This article is an open access article distributed under the terms and conditions of the Creative Commons Attribution (CC BY) license (https:// creativecommons.org/licenses/by/ $4.0 /)$.

\begin{abstract}
The possible adverse health effects of reduced physical activity (PA) on children and adolescents have been extensively documented as a result of the global obesity epidemic. However, the research has sometimes led to controversial results, due to the different methods used for the assessment of PA. The main aim of this review was to evaluate the association between PA and body composition parameters based on quantitative PA studies using the same equipment (Actigraph accelerometer) and cutoffs (Evenson's). A literature review was undertaken using PUBMED and Scopus databases. Subjects aged 6-15 were considered separately by sex. Weighted multiple regression analyses were conducted. From the analysis of fourteen selected articles, it emerged that $35.7 \%$ did not evaluate the association of sedentary time (ST) and moderate-to-vigorous physical activity (MVPA) with body composition, while the remaining $64.3 \%$ found a negative association of MVPA with BMI and fat mass with different trends according to sex. Furthermore, only $7.1 \%$ of these studies identified a positive association between ST and fat percentage. Based on the regression analyses conducted on the literature data, ST and MVPA were found to be significant predictors of body composition parameters, in addition to age and sex. Further studies using standardized methodologies to assess PA and body composition are needed. The inclusion of sex-disaggregated data may also be crucial to understand this phenomenon and to provide stronger evidence of the determinants of body composition in order to prevent the risk of obesity.
\end{abstract}

Keywords: accelerometer; sedentary behaviour; moderate-to-vigorous physical activity; age; sex; body composition

\section{Introduction}

The contribution of physical activity (PA) to a healthy lifestyle for children and adults is well known [1,2]. The prevention of overweight and obesity is one of the main benefits of PA in both children and adolescents. The role played by the PA should be well understood, considering that obesity prevalence has risen worldwide, even in rural areas [3,4]. In fact, previous studies have shown inconsistent results regarding the association between PA and adiposity or body mass index (BMI): increased activity is associated with a lower BMI [5,6], although PA interventions so far seem ineffective in improving the body mass index or body composition of children $[7,8]$. One possible explanation is that such interventions do not increase children's activity enough to affect adiposity.

According to Wilks et al. [9], PA would not be a major predictive factor for the changing of adiposity among children and adolescents. This is in contrast to the results of Kwon et al. [10], which are based on accelerometry data (moderate-to-vigorous physical activity (MVPA)) and accurate adiposity indicators (fat percentage $(\% \mathrm{~F})$ and fat mass 
index) in a longitudinal sample. This latest study concluded that maintaining 45 min of accelerometry-measured daily MVPA throughout childhood and adolescence constitutes an active lifestyle to prevent obesity in young adulthood. Confirming these outcomes, greater values of MVPA (assessed by accelerometry) were associated with a lower risk of obesity in children aged 9-11 years in the study by Katzmarzyk et al. [11]. Differences in PA measurements and adiposity indicators likely contributed to such inconsistent results $[9,12]$, hampering the comparisons of studies.

The definition of PA intensity is complex and confusing due to the different approaches used to evaluate it [13]. Many previous studies are based on the assessment of PA through questionnaires; these represent a weak substitute for objectively measured PA [14]. An overview of different PA assessment techniques can be found in McClung et al. [13]. In this review, we intend to focus on quantitative assessments and in particular on accelerometry.

The accelerometer measures the acceleration of the body, providing an objective assessment of PA intensity and total body movement (counts $\cdot \mathrm{min}^{-1}$ ) [15]. This device enables a large amount of data to be collected, but it has some limitations.

Considering the data from the literature, particular caution is needed as significant differences have been found between results obtained using different accelerometer brands [16]. Among the various accelerometers currently available, Actigraph (Pensacola, FL, USA) is one of the most widely used; the majority of experimental studies on PA and sedentary time (ST) use this type of accelerometer, with different types of signals (uniaxial or triaxial) [17]. Differences between uniaxial and triaxial accelerometry assessments are deemed negligible when applied to monitor daily routine, but not in specific sports [18-20].

In addition to the possible different outcomes from different brands of devices, there are also those related to the different cutoff points used to define the levels of PA. Trost et al. [15] assessed the classification accuracy of five different sets of cutpoints [21-25] for the Actigraph accelerometer for children and adolescents, concluding that the Evenson et al. [25] cutoff points are "the best overall performer across all intensity levels". In particular, an ST cutpoint of $100 \mathrm{cpm}$ showed excellent classification accuracy, as did a cutpoint of $\geq 2296 \mathrm{cpm}$ for moderate-to-vigorous physical activity (MVPA), proposed by Evenson et al. [25].

A further element of confusion is that many studies, even recent ones, evaluate the association of PA with body composition in mixed-sex samples. It is known that boys spend more time in MVPA than girls [26], and girls show a greater amount of fat than boys even during pre-puberty, with increasing differences in fat mass (FM) and fat-free-mass (FFM) during puberty $[27,28]$.

In consideration of the inconsistent and contradictory results for the association between PA and body composition parameters in children and adolescents, we collected only the studies using: (i) a homogeneous methodology to evaluate PA objectively, using in particular the Actigraph accelerometer and PA levels according to Evenson et al. cutoffs; (ii) data of PA and body composition parameters reported separately by sex. Through this strategy, we provided evidence on this topic based both on the existing literature, summarising the most relevant information, and on the results of statistical analyses carried out on the data collected by the selected studies. Therefore, this study supplies an overview of studies from literature investigating PA levels and body composition parameters during childhood and adolescence, on the other. In addition, it assesses the importance of sex, age, ST and MVPA as determinants of BMI, \%F, and fat free mass index (FFMI).

This study hence provides a contribution to the current knowledge, giving useful insights into how PA and body composition relate to one another and how to develop future research strategies.

\section{Materials and Methods}

\subsection{Searching Strategy}

This is a scoping review [29] of existing studies involving PA and body composition in school-aged children and adolescents. This review was carried out in accordance with 
PRISMA guidelines [30,31] (Figure 1). The articles published between January 2010 and January 2020 were systematically searched on PUBMED/MEDLINE and Scopus.

The search strategy used all the combinations with the following words: ("accelerometer" OR "Actigraph") AND ("body composition" OR "adiposity" OR "fat mass" OR "fatness" OR "fat free mass").

Two reviewers (E.G.-R. and N.R.) selected the relevant studies separately based on the titles and abstracts. Then, all the authors independently reviewed the full text of the selected studies to decide on their final suitability according to the inclusion and exclusion criteria. The references of selected studies were reviewed to search for further studies to be included in this research.

The following information was collected from each included article: authors, year of publication, study name (if present) and design, sample size, mean age and country of subjects included in the study, ST, MVPA and anthropometric parameters (stature, weight, BMI, \%F, FM, FFM and FFMI).
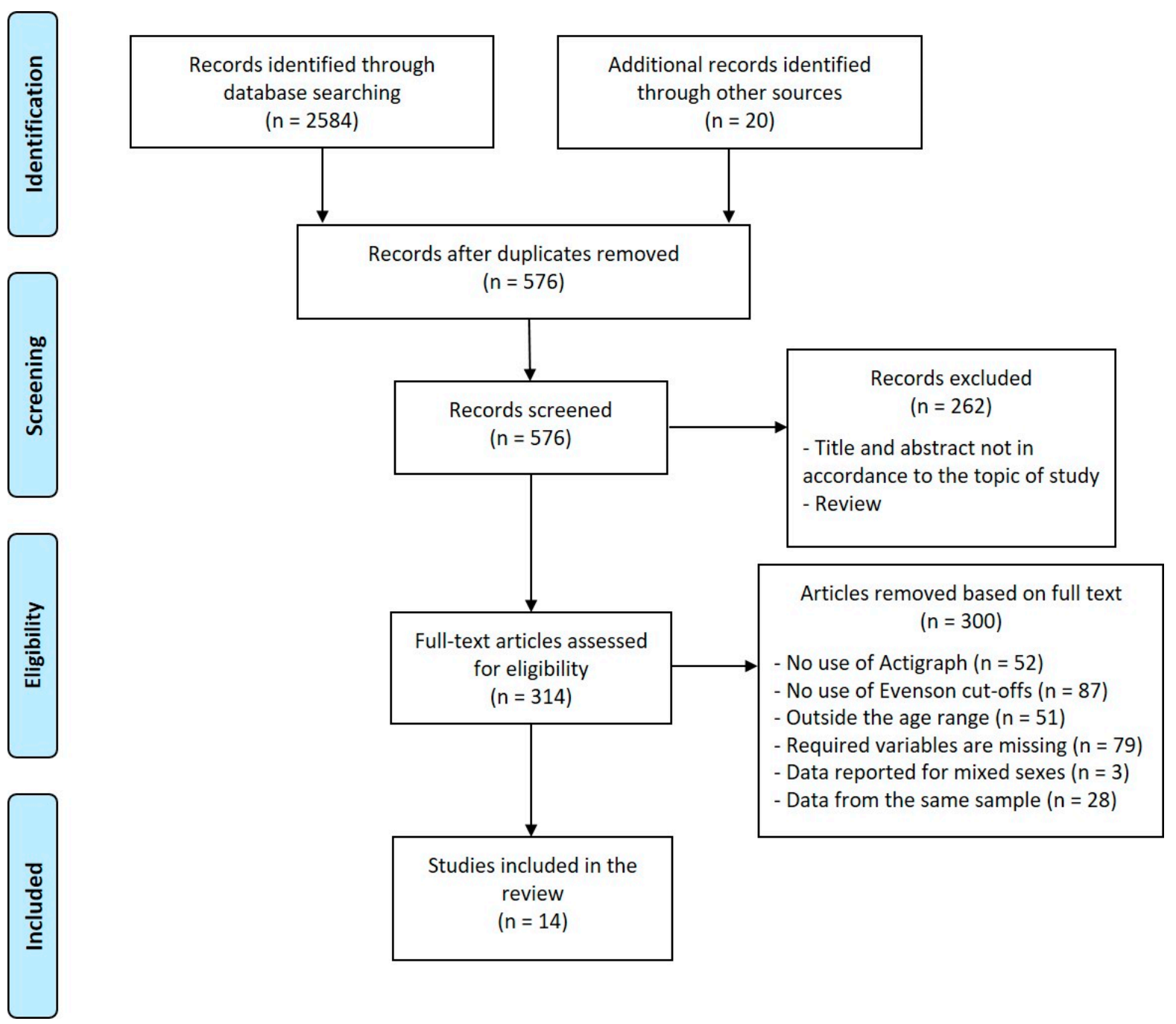

Figure 1. Flowchart detailing the search for eligible studies.

\subsection{Criteria for Inclusion and Exclusion}

Articles were selected through database searches using the following inclusion criteria: (1) PA intensity detected with an Actigraph accelerometer; (2) classification of PA intensity by cutoffs in accordance with Evenson et al. [25]; (3) mean age of the sample in the 6-15 year range; (4) the minimum variables required to enter into the review were ST, MVPA, \%F 
and FFM; (5) data were reported separately by sex. The BMI and FFMI values within the baseline characteristics of participants were deemed important, but not decisive. If some of these characters were not reported, the study was nevertheless included when missing data could be obtained by calculation from the other data reported by the authors (e.g., MVPA $=$ moderate PA $(\mathrm{MPA})+$ vigorous PA $(\mathrm{VPA}) ; \% \mathrm{~F}=(\mathrm{FM} /$ weight $) * 100$; etc. $)$.

In addition, we included longitudinal studies collecting only baseline data. When they did not include the chosen variables or the age of the participants was out of the chosen range, we selected the first useful data from subsequent surveys.

In the case of several articles referring to subsamples taken from the same main study, we chose the most informative one on the basis of included variables and, as the next criterion, the study with the largest subsample size.

Exclusion criteria were the following: (1) studies not published in English; (2) studies using only pedometer/step counters; (3) studies carried out on subjects suffering from medical pathologies; (4) studies conducted on athletes or subjects examined for accelerometry during motor exercises or performance tests; (5) studies reporting results from mixed-sex samples; (6) studies concerning preschool children, adults or the elderly. Reviews, editorials, and study protocols were excluded. Some articles were not included for more than one reason. Figure 1 shows the main reasons; a mixed-sex data presentation was the most frequent additional reason.

\subsection{Examined Variables}

First, we chose ST, namely the time spent in sedentary behaviour, and MVPA, a category of activity intensity. ST and MVPA (or, when missing, moderate physical activity (MPA) and vigorous physical activity (VPA)), were objectively determined by an Actigraph accelerometer for several consecutive days using specific cutoff points (ST $\leq 100 \mathrm{cpm}$, MVPA $\geq 2296 \mathrm{cpm}$ or MPA $=2296-4011 \mathrm{cpm}$ and VPA $\geq 4012 \mathrm{cpm})[15,25]$. ST and PA were reported as ST and MVPA (or MPA and VPA) per day (min/day).

Among the anthropometric characters and indices, we collected data on stature, weight, BMI, \%F, FM, FFM and FFMI. The BMI was determined as follows: weight (kg)/ stature squared $\left(\mathrm{m}^{2}\right)$. FFMI was determined as follows: FFM $(\mathrm{kg}) /$ stature squared $\left(\mathrm{m}^{2}\right)$.

Four methods were used to assess the body composition parameters in the eligible studies: anthropometry (\%F was estimated by skinfolds through specific equations); bioimpedance analysis (BIA); dual energy X-ray absorptiometry (DXA) (total body fat mass was derived from the DXA scan images); deuterium dilution method (DLW). The evaluation method used in the analysed studies is given in Table 1. 


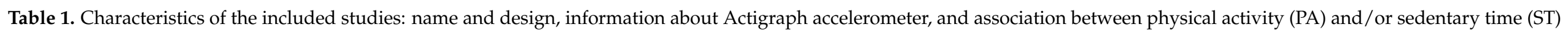
and body composition parameters.

\begin{tabular}{|c|c|c|c|}
\hline Reference & Study Name and Design & Accelerometer: Model, Location, Duration & $\begin{array}{l}\text { Conclusions on the Association of PA or } \\
\text { ST with Body Composition }\end{array}$ \\
\hline Ben Jemaa et al., 2018 [32] & Cross-sectional study & $\begin{array}{c}\text { Actigraph GT3X+ on the right hip at least for } 3 \\
\text { weekdays and } 1 \text { weekend day }\end{array}$ & $\begin{array}{c}\text { MVPA was negatively correlated with } \\
\% \text { Fat (mixed sexes) }\end{array}$ \\
\hline Benitéz-Porres et al., 2016 [33] & Cross-sectional study & $\begin{array}{l}\text { Actigraph GT3X on the right hip. Only } \\
\text { participants with } \geq 4 \text { complete days, including } 1 \\
\text { weekend day, were included. A day was } \\
\text { considered valid if it contained } \geq 10 \mathrm{~h} \text { of wear } \\
\text { time for weekdays and } \geq 8 \mathrm{~h} \text { for weekend days }\end{array}$ & not assessed \\
\hline Bernhardsen et al., 2019 [34] & $\begin{array}{l}\text { Part of Norwegian Mother and Child Cohort Study } \\
\text { (MoBa), a prospective population-based cohort } \\
\text { study. Data from a sub-cohort of } 1603 \text { participants } \\
\text { born between } 2002 \text { and } 2004\end{array}$ & $\begin{array}{l}\text { Actigraph GT3X+ on right hip of all participants } \\
\text { providing at least one valid day }\end{array}$ & $\begin{array}{l}\text { MVPA was negatively associated with } \\
\text { BMI and FM only in boys }\end{array}$ \\
\hline Chaput et al., 2012 [35] & $\begin{array}{c}\text { QUebec Adiposity and Lifestyle InvesTigation in } \\
\text { Youth (QUALITY) } \\
\text { Cross-sectional study }\end{array}$ & $\begin{array}{c}\text { Actigraph LS } 7164 \text { on the right hip. A valid day } \\
\text { was defined as } 10 \text { or more hours of monitor wear } \\
\text { time; respondents with four or more valid days } \\
\text { were retained for analyses }\end{array}$ & $\begin{array}{c}\text { MVPA was negatively associated with } \\
\text { \%Fat (mixed sexes). } \\
\text { No association for ST. }\end{array}$ \\
\hline
\end{tabular}

Part of the International Study of Childhood Obesity, Lifestyle and the Environment (ISCOLE), a

Ferrari et al., 2015 [36] multinational cross-sectional study conducted in twelve countries (Australia, Brazil, Canada, China, Colombia, Finland, India, Kenya, Portugal, South Africa, United Kingdom, and United States). Here there are data only from Brazilian sample

Actigraph GT3X+ worn at the hip on an elasticized belt, on the right midaxillary line, at least for 4 days (including at least one weekend day) with at least $10 \mathrm{~h} /$ day of waking wear time
MVPA was negatively associated with BMI and \%Fat in males (VPA in females). No association for ST.
Actigraph was worn at the hip for a minimum of $10 \mathrm{~h}$ of wearing time per day and at least 4 days including one weekend day
MVPA was negatively associated with Fat Mass, \%Fat, Fat Mass Index only in girls (VPA with the same traits in boys) 
Table 1. Cont.

\section{Reference}

Hallal et al., 2013 [38]

Study Name and Design

A subsample of the 1993 Pelotas (Brazil) Birth Cohort study at the mean age of 13.3 years. Cross-sectional

\section{Accelerometer: Model, Location, Duration}

Actigraph GT1M worn on the left side of the hip for 6 days. Days with $<600 \mathrm{~min}$ of registered data and periods of time above $60 \mathrm{~min}$ of consecutive zero counts were excluded
IDEFICS study (Identification and prevention of dietary- and lifestyle-induced health effects in children and infants), a prospective

Herrmann et al., 2015 [39] population-based cohort study of children from 7 European countries

Part of Iowa Bone Development Study- a longitudinal study investigating bone health and body composition in seven measurement waves at approximate ages 5 years (yr) (wave 1), 8 yr (wave 2) -used in this review-, $11 \mathrm{yr}$ (wave 3), $13 \mathrm{yr}$ (wave 4), $15 \mathrm{yr}$ (wave 5), $17 \mathrm{yr}$ (wave 6), and $19 \mathrm{yr}$ (wave 7)

Part of research related to Finnish Schools ' on the Move program (LIKES Research Centre for Physical Activity and Health)-longitudinal- 2013

Joensuu et al., 2018 [41]

Cross-sectional study

McCormack et al., 2016 [42]

Cross-sectional study

A school-based cluster randomized controlled trial (clinical trial registry: ISRCTN76013675) to evaluate

Sardinha et al., 2017 [44]

the impact of an intervention in childhood obesity between 2010 and 2011- cross-sectional and
ActiTrainer or GT1M Actigraph uniaxial

accelerometers worn on right hip for three consecutive days, including 1 weekend day, for at least $6 \mathrm{~h}$ per day. Both types of accelerometers have been observed to measure comparable MVPA levels (except for lower PA levels).

Actigraph uniaxial accelerometers model 7164 in waves 1 to 4 (used in this study), model GT1m in wave 5 , and model GT3x+ in waves 6 and 7 for a least $10 \mathrm{~h}$ /day and a minimum of $3 \mathrm{~d}$ within 15 months of the DXA scan, worn at the hip on the midaxillary line

Actigraph GT3X+ at the hip, for at least 2 weekdays and 1 weekend day, $17 \mathrm{~h} /$ day.

not assessed

Actigraph G3TX + accelerometers worn on the right hip for at least 3 valid weekdays and 1 valid weekend day. One day was considered valid if the child had a minimum of $10 \mathrm{~h}$ of wear time during waking hours.

MVPA was negatively associated with Fat Mass in both males and females. No association for ST.

Actigraph GT3X worn on the right hip for at least 2 weekdays and 1 weekend day. A minimum recording of $8 \mathrm{~h}$ /day was the criteria to accept daily PA

GT1M Actigraph worn on the right hip for at least three days of recording (two weekdays and one weekend day). A minimum of $600 \mathrm{~min}$ was required for inclusion in the analysis
MVPA was negatively correlated with $\%$ Fat in mixed sexes and boys (no in females).

ST was positively correlated with \%Fat in mixed sexes and boys (no in females).

MVPA was significantly greater in norma weight than in overweight and obese.

ST did not differ.
MVPA was negatively associated with Fat

Mass (mixed sexes).

No association for ST.
Conclusions on the Association of PA or ST with Body Composition

not assessed

not assessed prospective study 


\subsection{Statistical Analysis}

From the 14 studies examined, we collected the outcomes relative to 6558 apparently healthy subjects (3179 males, 3379 females), which were used for statistical purposes.

To test the association between a single continuous dependent variable (BMI or \%F or FFMI) and several independent variables (sex, age, ST and MVPA), multiple linear regression models were used. The "weight" option to adjust the contribution of each study in proportion to their sample size to the outcome of the multiple regression was applied in this analysis. Multicollinearity between variables was assessed through variance inflation factors (VIFs), with values less than 10 considered acceptable [45].

All statistical analyses were carried out using STATISTICA for Windows (version 11.0, StatSoft, Tulsa, OK, USA). The level of significance was set at $p \leq 0.05$.

\section{Results}

\subsection{Description of Included Studies}

A total of 2604 records were identified: 2584 through database searches and 20 additional records by reference list searches. After removing duplicates, 576 records were screened; 262 were excluded by reading titles and abstracts, so the full text of 314 articles was assessed for eligibility. 300 articles were removed according to inclusion and exclusion criteria, leading to the inclusion of 14 original studies. Figure 1 shows a flowchart of the process of selecting articles.

Table 1 shows study design, type of accelerometer used to assess PA, and association of MVPA or ST with body composition parameters. Five out of fourteen studies did not analyse the association between MVPA and ST with body composition parameters this $[26,33,38,39,41]$. Three of the remaining nine studies found a negative association of MVPA with BMI and FM only in boys [34,36,42], one only in girls [37], one in both boys and girls [40] and three in mixed sexes [32,35,44]. Finally, the residual study observed higher MVPA values in normal weights than in overweight/obese children [43]. No association was shown between ST and body composition parameters, except in the study of McCormack et al. [42], where ST was positively correlated with \%F in boys and mixed sexes.

Tables 2 and 3 show the characteristics of the studies included in the review for males and females, respectively, according to sample size, age, country, ST, MVPA, stature, weight, $\mathrm{BMI}$, and body composition parameters (\%F, FM, FFM and FFMI).

For the research focused on males, three studies included subjects with a mean age between 8 and 9 years [39,40,43], five with a mean age between 9 and $10[26,32,35,37,44]$, four between 10 and 11 [33,34,36,42], two between 12 and 13 [38,41] and one study with a mean age of 15.4 [33]. For the research focused on females, there were three studies with a mean age range between 8 and $9[39,40,43]$, six between 9 and $10[26,32,35,37,42,44]$, three between 10 and $11[33,34,36]$ and one study each for mean ages of 12.4 [41], 13.1 [38] and 15.2 years [33].

Most of the included studies were performed in developed countries. Seven studies were carried out in Western Europe [33,34,37,39,41,43,44], three in North America [35,40,42] and the remaining four studies in developing countries (two in Brazil [36,38] and two in Africa [26,32]). For research involving both sexes, $9 \%$ lived in developing countries and the remaining $91 \%$ in developed countries. Two articles were published by $2014[35,38]$ and the remaining 12 were published in 2015-2019 [26,32-34,36,37,39-44].

The majority were descriptive cross-sectional studies $(n=9,64.3 \%)[26,32,33,35-38,42,43]$. Four studies (28.6\%) were prospective cohort studies [34,39-41] and one study $(7.1 \%)$ was cross-sectional and prospective [44].

With regard to the body composition assessment, six studies (42.9\%) used DXA [34,35,40,42-44], four (28.6\%) used BIA [36,37,39,41], three (21.4\%) used DLW [26,32,38] and one $(7.1 \%)$ used skinfold thicknesses [33]. Almost all the studies reported \%F (mainly) and/or FM and FFM. Only one reported FFMI [41]. Of fourteen studies, half included BMI values $[33,34,36,37,41,43,44]$. 


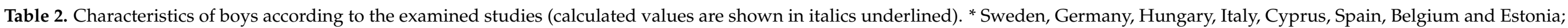
$\S$ values converted from hour $/$ day to min/day; $\mathrm{a}=\mathrm{BIA} ; \mathrm{b}=\mathrm{DXA} ; \mathrm{c}=\mathrm{DLW} ; \mathrm{d}=$ skinfolds.

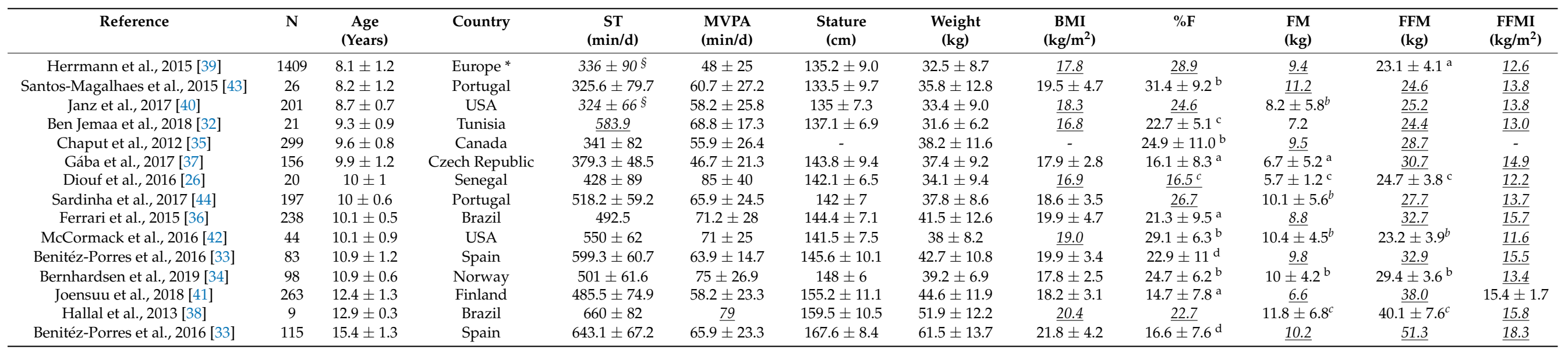

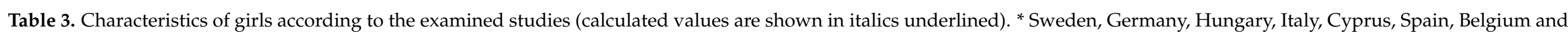
Estonia; $\S$ values converted from hour/day to min/day; a = BIA; b = DXA; $=$ DLW; $d=$ skinfolds.

\begin{tabular}{|c|c|c|c|c|c|c|c|c|c|c|c|c|}
\hline Reference & $\mathbf{N}$ & $\begin{array}{c}\text { Age } \\
\text { (Years) }\end{array}$ & Country & $\begin{array}{c}\mathrm{ST} \\
(\mathrm{min} / \mathrm{d})\end{array}$ & $\begin{array}{c}\text { MVPA } \\
(\mathrm{min} / \mathrm{d})\end{array}$ & Stature (cm) & Weight (kg) & BMI $\left(\mathrm{kg} / \mathrm{m}^{2}\right)$ & $\% \mathrm{~F}$ & $\begin{array}{l}\text { FM } \\
(\mathrm{kg})\end{array}$ & $\begin{array}{l}\text { FFM } \\
\text { (kg) }\end{array}$ & $\begin{array}{c}\text { FFMI } \\
\left(\mathrm{kg} / \mathrm{m}^{2}\right)\end{array}$ \\
\hline Herrmann et al., 2015 [39] & 1544 & $8.1 \pm 1.2$ & Europe* & $342 \pm 90 \S$ & $36 \pm 18$ & $134.7 \pm 9.1$ & $32.1 \pm 8.3$ & 17.7 & $\underline{33.6}$ & $\underline{10.8}$ & $21.3 \pm 4.0^{\mathrm{a}}$ & $\underline{11.7}$ \\
\hline Santos-Magalhaes et al., 2015 [43] & 24 & $8.4 \pm 1$ & Portugal & $347.1 \pm 66.5$ & $52.1 \pm 16.5$ & $133.6 \pm 6.8$ & $36 \pm 8.7$ & $20.0 \pm 3.5$ & $37.3 \pm 6.4^{b}$ & $\frac{10.0}{13.4}$ & 22.6 & 12.7 \\
\hline Janz et al., 2017 [40] & 214 & $8.7 \pm 0.6$ & USA & $330 \pm 66 \S$ & $40.6 \pm 18.9$ & $133.0 \pm 6.8$ & $32 \pm 8.7$ & 18.1 & $29.1^{\mathrm{b}}$ & $9 . \overline{3 \pm 5.9}$ & $\overline{22.7}$ & 12.8 \\
\hline Ben Jemaa et al., 2018 [32] & 19 & $9.4 \pm 1$ & Tunisia & 498.8 & $49.8 \pm 22.7$ & $139.6 \pm 8.3$ & $36.1 \pm 8.6$ & 18.5 & $31.1 \pm 8.2^{c}$ & 11.2 & 24.9 & 12.8 \\
\hline Chaput et al., 2012 [35] & 251 & $9.6 \pm 0.9$ & Canada & $34 \overline{34} 82$ & $37.5 \pm 17.9$ & - & $38 \pm 11.2$ & $\overline{-}$ & $30.3 \pm 10.0^{\mathrm{b}}$ & $\overline{11.5}$ & 26.5 & - \\
\hline Gába et al., 2017 [37] & 209 & $9.8 \pm 1.3$ & Czech Republic & $394.4 \pm 51.7$ & $37.4 \pm 16.7$ & $142.5 \pm 8.9$ & $35.8 \pm 8.8$ & $17.4 \pm 2.8$ & $18.1 \pm 7.3^{\mathrm{a}}$ & $6.9 \pm 4.4^{\mathrm{a}}$ & 28.9 & 14.2 \\
\hline Sardinha et al., 2017 [44] & 189 & $9.9 \pm 0.6$ & Portugal & $525.4 \pm 67.1$ & $53.7 \pm 18.4$ & $143 \pm 7$ & $39.7 \pm 8.6$ & $19.1 \pm 3.2$ & 30.5 & $12.1 \pm 5.1^{b}$ & $\overline{27.6}$ & 13.5 \\
\hline McCormack et al., 2016 [42] & 43 & $10.0 \pm 0.8$ & USA & $580 \pm 48$ & $51 \pm 22$ & $140.0 \pm 6.5$ & $35.0 \pm 7.0$ & 17.9 & $31.5 \pm 6.1^{b}$ & $10.3 \pm 4.0^{b}$ & $20.7 \pm 3.5^{b}$ & $\frac{10.6}{10.6}$ \\
\hline Benitéz-Porres et al., 2016 [33] & 63 & $10.7 \pm 1.3$ & Spain & $609 \pm 61.2$ & $61.3 \pm 12.7$ & $143.2 \pm 10.9$ & $40 \pm 12.7$ & $19.1 \pm 4.0$ & $22.9 \pm 6.6^{\mathrm{d}}$ & $\overline{9.2}$ & $\overline{30.8}$ & $\overline{15.0}$ \\
\hline Bernhardsen et al., 2019 [34] & 88 & $11.0 \pm 0.6$ & Norway & $508.0 \pm 55.6$ & $59 \pm 17.4$ & $149 \pm 8$ & $40 \pm 8.4$ & $17.9 \pm 2.3$ & $28.1 \pm 5.8^{b}$ & $11.5 \pm 4.6^{\mathrm{b}}$ & $28.6 \pm 4.8^{\mathrm{b}}$ & 12.9 \\
\hline Joensuu et al., 2019 [41] & 331 & $12.4 \pm 1.3$ & Finland & $511.0 \pm 66.6$ & $47.3 \pm 18.0$ & $155.1 \pm 9.3$ & $45.7 \pm 10.2$ & $18.8 \pm 3.0$ & $20.4 \pm 6.9^{a}$ & 9.3 & $\underline{36.4}$ & $14.8 \pm 1.4$ \\
\hline Hallal et al., 2013 [38] & 16 & $13.1 \pm 0.3$ & Brazil & $661 \pm 78$ & 64 & $159 \pm 5.6$ & $51.7 \pm 9.5$ & $\underline{20.5}$ & $\underline{30.2}$ & $15.6 \pm 5.8^{c}$ & $37.3 \pm 6.5^{c}$ & $\underline{14.8}$ \\
\hline Benitéz-Porres et al., 2016 [33] & 119 & $15.2 \pm 1.4$ & Spain & $642.7 \pm 83.4$ & $48.1 \pm 18.9$ & $160.2 \pm 6$ & 57.5 & $22.4 \pm 4.6$ & $21.2 \pm 7.7^{\mathrm{d}}$ & 12.2 & $\underline{45.3}$ & $\underline{17.7}$ \\
\hline
\end{tabular}




\subsection{General Overview}

We performed three weighted multiple linear regression models to test the simultaneous influence of age, PA amount (examined through minutes per day of ST and MVPA) and sex on FFMI, BMI and \%F (Table 4). The variables used as predictors exerted a significant effect, as shown by the $\mathrm{R}^{2}$ value, on the dependent variable considered $(p<0.001$ in all three models). The three models, obtained using the same four independent variables, predicted respectively $78 \%, 62 \%$ and $71 \%$ of the overall variance in FFMI, BMI and $\%$ F. The VIF values were acceptable in all the analyses.

The outcomes of multiple linear regression analysis with FFMI as the dependent variable showed that, after controlling for other covariates, the decrease in ST and the increase in age, in addition to being a male, were associated with significantly higher FFMI values. According to the outcomes of multiple linear regression with BMI as the dependent variable, the increases in ST and age and being a male were associated with significantly higher BMI values, while the increase in MVPA was associated with significantly lower BMI values. The last regression analysis was carried out by considering $\% \mathrm{~F}$ as the dependent variable. This analysis shows that the increase in ST and the decreases in MVPA and age, in addition to belonging to the female sex, were associated with significantly increased $\% \mathrm{~F}$.

Table 4. Predictors of FFMI, BMI and \%F: results of multiple regression analyses.

\begin{tabular}{cccccccccc}
\hline \multirow{2}{*}{ Predictors } & \multicolumn{3}{c}{ FFMI } & \multicolumn{3}{c}{ BMI } & \multicolumn{3}{c}{ \%F } \\
\cline { 2 - 10 } & $\boldsymbol{\beta}$ & $\mathbf{t}$ & $\boldsymbol{p}$ & $\boldsymbol{\beta}$ & $\mathbf{t}$ & $\boldsymbol{p}$ & $\boldsymbol{\beta}$ & $\mathbf{t}$ & $\boldsymbol{p}$ \\
\hline Age & 0.935 & 111.445 & 0.000 & 0.312 & 18.322 & 0.000 & -0.933 & -71.602 & 0.000 \\
MVPA & 0.006 & 0.449 & 0.653 & -0.074 & -4.005 & 0.000 & -0.059 & -3.845 & 0.000 \\
ST & -0.098 & -5.489 & 0.000 & 0.546 & 23.699 & 0.000 & 0.259 & 14.849 & 0.000 \\
Sex (male) & 0.234 & 21.116 & 0.000 & 0.087 & 6.102 & 0.000 & -0.325 & -26.335 & 0.000 \\
$\mathrm{R}^{2}$ & 0.776 & & & 0.624 & & & 0.705 & & \\
$\mathrm{R}^{2}$ adj & 0.776 & & & 0.623 & & & 0.705 & & \\
$p$ & $<0.001$ & & & $<0.001$ & & & $<0.001$ & & \\
\hline
\end{tabular}

In particular, MVPA was negatively associated with BMI $\left(0.007 \mathrm{~kg} / \mathrm{m}^{2}\right.$ of BMI decrement every minute per day of MVPA increment, unstandardized parameter B, not presented in Table 4$)$ and $\% \mathrm{~F}(0.03$ percent points of $\% \mathrm{~F}$ decrement every minute per day of MVPA increment). ST was negatively associated with FFMI $\left(0.002 \mathrm{~kg} / \mathrm{m}^{2}\right.$ of FFMI decrement every minute per day of ST increment) and positively associated with BMI and $\% \mathrm{~F}\left(0.006 \mathrm{~kg} / \mathrm{m}^{2}\right.$ and 0.015 percentage points increment, respectively, every minute per day of ST increment). In addition, sex proved to be a significant predictor for all dependent variables: being a male increased FFMI and BMI (with an increment of $0.38 \mathrm{~kg} / \mathrm{m}^{2}$ and only $0.09 \mathrm{~kg} / \mathrm{m}^{2}$, respectively, in comparison to girls) and decreased $\% \mathrm{~F}$ (1.82 percentage points).

\section{Discussion}

This review aimed to evaluate the association between PA and body composition parameters in children and adolescents. After a detailed analysis of the 14 articles that met the criteria for inclusion, with a total sample of 6558 apparently healthy participants (48.5\% males), a tendency towards a decrease in body adiposity with increasing MVPA and decreasing ST was evident.

PA is a complex and multi-dimensional behaviour associated with several health outcomes. Its correct quantification is therefore crucial for population assessment and possible interventions to be implemented. PA assessment can be done both using questionnaires and device-based techniques. As self-reported measures of PA have proved to have several limitations [46,47], accelerometry is the most used field method in free-living subjects to assess PA due to its accuracy and reliability.

In this review, we examined the association between objectively assessed PA (by means of an Actigraph accelerometer) and body composition parameters in children and adolescents using outcome data from 14 studies. Accelerometers offer the possibility of 
non-invasive and objective estimation of PA intensity levels using "activity counts" to classify PA as light, moderate, or vigorous intensity, in addition to ST. Accelerometers, used for approximately twenty years for children and adolescents [48], have now also become widely used in large-scale studies [49]. These devices are commonly worn on the wrist or the hip, with the latter placement ensuring better accuracy [50].

The different location of the device, the different types of accelerometers used, and the different cutoff points that define the PA level are some of the factors that make it difficult to compare results across studies.

For this reason, we decided to include in this review only the studies that assessed PA through a hip-worn accelerometer Actigraph (the most widely used device) and used the cutoffs reported by Evenson et al. [25]. It is important to underline that differences in the accelerometer cutpoints used can lead to different PA intensities [51] and that Evenson's cutoffs are highly recommended as they are deemed to provide an optimal estimate of PA in children aged $5-15$ years [52].

It should be noted that several different Actigraph models have been used in the selected articles. The majority of activity counts were recorded by GT3X or GT3X+ models, but five studies used the original 7164 and the GT1M models. Recent literature shows that accelerometer counts and time spent in MVPA as recorded by the Actigraph GT1M, GT3X and GT3X+ are compatible with one another [52]. Moreover, the vertical axis counts recorded by the 7164 and GT1M models are generally deemed highly comparable $[53,54]$, although there is no unanimous consensus [55]. Though differences between uniaxial and triaxial accelerometric counts are apparent in specific sports [56], negligible differences are seen in daily routine activity [20].

In summary, it can be asserted that different Actigraph models, especially the more recent generations of accelerometers, provide data that can be accurately and reliably compared.

Another point of discussion is the reliability of the accelerometers used to assess PA. In literature, there are some studies focused on the assessment of the inter-instrument reliability of different accelerometers, by comparing the outputs from accelerometers worn on opposite hips or by using high-precision devices to examine technical reliability over multiple trials. A review by Trost et al. [57] summarized some of the results reported by the literature on this topic up to 2004, concluding that nearly all the studies reported high precision reliability [57]. One more recent study published by Aadland and Ylvisåker [58] in 2015 described the results of the assessment of the inter-instrument reliability of the Actigraph GT3X+ in adults. The results showed that the reliability of the accelerometer, tested wearing two accelerometers simultaneously on the contralateral hips for 21 days, was very high and that the Actigraph GT3X+ accelerometer was a reliable tool for measuring PA in adults [58]. Only a few studies have been published on inter-instrument reliability in children. Trost et al. [59] calculated the reliability of two Actigraph accelerometers worn on the left and right hips on thirty children aged 10-14 years. The results indicated an excellent intraclass reliability coefficient $(\mathrm{ICC}=0.87$ ). Another more recent study examined the interinstrument reliability for eight children with cerebral palsy using an Actigraph GT3X+; it concluded that this is a reliable and valid device to monitor PA during walking [60].

\subsection{Trend of PA and Body Composition with Age, Sex and Population}

The examined studies defined ST as $<100 \mathrm{cpm}$, including any waking behaviour characterized by an energy expenditure of $\leq 1.5$ metabolic equivalents (METs) in a sitting or reclining position [61]. MVPA was defined as a combination of moderate and vigorous physical activity, including any activity over 3 METs [62]. The children spent most of their time (min/day) in sedentary behaviours rather than in moderate/vigorous activities: from $44 \%$ [40] to $67.3 \%$ [42] in ST vs. $5.4 \%$ [37] to 9.35\% [26] in MVPA. In particular, in studies focused on females only, three studies had average MVPA values that met WHO recommendations; two of these were carried out in developing countries (Senegal [26] and Brazil [38]) and only one was carried out in a developed country (Spain [33]). For studies focusing on males, the situation was better: all the studies carried out in developing 
countries $[26,32,36,38]$ and approximately half of the studies carried out in developed countries [33,34,42-44] had mean values of MVPA higher than recommended.

Several studies (among the selected ones) evaluated the frequency of children within the study sample that complied with these recommendations for children and youths by the WHO. The majority of Norwegian children satisfied the recommended PA level of $\geq 60 \mathrm{~min} / \mathrm{d}$ of MVPA [34], as did Senegalese children aged 8-11 (55\% according to Diouf et al. [26]), American children aged 9-12 (55\% according to McCormack et al. [42]) and Tunisian children aged 8-11 (47.5\% according to Ben Jeema et al. [32]). Only 14\% of Czech children aged 7-12 [37], 20.1\% of European children aged 6-10 [39], 24.7\% of Canadian children aged 8-10 [35], and 33.7\% of Finnish children aged 9-15 [41] were found to have done at least 60 min of daily MVPA.

Studies reporting data separately by sex show higher frequencies of MVPA in males than in females, with percentages decreasing from developing to developed countries, as follows: $66.7 \%$ of Tunisian boys vs. $26.3 \%$ of girls [32]; $52.2 \%$ of Senegalese boys vs. $47.8 \%$ of girls [26]; $44.9 \%$ of Finnish boys vs. $24.2 \%$ of girls [41]; $36 \%$ of Canadians boys vs. $11 \%$ of girls [35]; $30.6 \%$ of European boys vs. $10.5 \%$ of girls [39]; $22 \%$ of Czech boys vs. $8 \%$ of girls [37]. An exception to this trend is represented by the study of McCormack et al. [42], which reported the highest frequencies of MVPA of our review in US children ( $75 \%$ boys and $35 \%$ girls).

The lack of an acceptable gold standard for measuring the body composition of children implies that several techniques were used, from the simple BMI to DXA. Half of the examined studies evaluated BMI as a proxy for adiposity. Moreover, other body composition parameters (\%F, FM, FFM, FFMI) were assessed by plicometry $(7.1 \%)$, BIA $(28.6 \%)$, DLW (21.4\%) and DXA (42.9\%). In particular, it should be noted that only one of the 14 studies analyzed used skinfolds as a measure.

Changes in body composition parameters occur during childhood, even if less pronounced than during infancy. Sex differences in body composition, present throughout childhood, appear more pronounced during adolescence due to the effect of gonadal sex steroids. Sex-specific differences become evident during this phase of growth: females show greater FM and lower FFM than males [63,64]. Consistent with this trend, our statistical analysis on the cross-sectional data collected in the selected studies showed a decrease in \%F with age, especially in males, and an increase in FFMI and BMI, in males and females, respectively. The assessment of these parameters is very important due to the association of the amount of adult visceral adipose tissue with BMI changes during adolescence, as verified by longitudinal design [65].

If we analyze the body composition of the participants divided by developed and developing countries, is clear that males from African countries (Tunisia and Senegal) have the lowest mean BMI (also \%F and FFMI in Senegalese boys) among the other studies reporting data for individuals of the same age. Brazilian subjects, however, have higher mean BMI, but similar \%F and FFMI, as compared to individuals from other countries. Such differences were not present in the female sex.

\subsection{Association between PA and Body Composition Parameters}

The impact of sedentary behaviour on health has been investigated by many studies, with particular reference to the relationship between sedentary behaviour and childhood obesity or other health outcomes [66-69]. In recent years, the excess of adiposity in developing countries and the need for intervention to increase PA were largely reported in the literature [70-72]. Ferrari et al. [73] found that self-reported measures significantly underestimated sedentary time and overestimated PA time compared to device measures. Moreover, regression models showed that self-reported PA and sedentary behaviour were not significantly associated with health outcomes, unlike objectively-measured PA and ST. Therefore, self-reported methods may underestimate the strength of some relationships between activity and body composition. 
The current study adds to the existing knowledge by providing the findings of the associations between PA (objectively assessed) and body composition parameters on a very large sample of children and adolescents taken from the literature.

The results obtained using multiple regression analysis show that the strength of the association of BMI, \%F, and FFMI with MVPA and ST was also influenced by age and sex. It is important to underline the effect of sex on these associations, which has often been neglected in the literature. In our study, PA assessed by accelerometry resulted in a significant predictor of body composition parameters. The regression models explained a high and significant percentage of the variance in the body composition parameters. In particular, our analyses showed that MVPA was negatively associated with BMI and \%F, and ST was negatively associated with FFMI but positively associated with BMI and \%F. Subjects who spent more time engaged in MVPA showed lower weight status and lower levels of adiposity, and subjects who were more sedentary had higher weight status and $\% \mathrm{~F}$ and lower FFMI.

Thus, MVPA had a significant and positive effect on adiposity and consequently on health indicators, but not on FFMI. This is likely because the examined samples were not very physically active.

From our findings, it seems that youths living in developing countries are more physically active than those living in developed ones. Since overweight/obese youth are generally less active than normal/underweight ones [26], the lower overweight/obesity prevalence in developing countries could explain these differences. This assumption is in agreement with a cross-sectional study carried out in Tunisia, where the percentage of normal-weight children who spent more than $60 \mathrm{~min}$ a day in MVPA $(60.9 \%)$ was significantly higher than in overweight children (29.4\%) (according to data tabulated by Ben Jeema et al. [32]).

However, the study by Guthold et al. [74] gave inconsistent results; there was no increase in the prevalence of insufficient activity with country income, as was seen in high-income Asia Pacific countries. It should be noted that in this review there was no data from Asian countries.

\subsection{Strength and Limitations}

The collection of evidence by this scoping review is valuable in supplying an overview of the literature, with the intent of identifying where evidence gaps exist in order to assist future studies. This scoping review has several strengths, which include a systematic search of literature articles and consideration of a wide range of evidence. In particular, the major strengths of this review are that it includes only research that objectively measured ST and MVPA using the same accelerometer brand placed at the hip as well as the same cutpoints for PA classification.

The main limitation is common to any scoping review: it does not involve a quality assessment. Among the other limitations of this study, there is the use of BMI as an indicator of adiposity $[75,76]$; its accuracy is believed to increase in accordance with the degree of body fatness [77]. The lack of standard protocols for the detection of the body composition parameters used (\%F, FM, FFM and FFMI) is another limitation to this review. The interchangeability of body composition parameters obtained by different methods is controversial. The minimal differences between BIA and DXA outcomes found in subjects aged 16-18 suggest that these methods may be interchangeable at the population level according to Achamrah et al. [78]. However, these findings contrast with those obtained by Lee et al. [79], indicating an overestimation of whole body muscle mass and skeletal muscle mass assessed by BIA as compared to DXA, especially in men. Moreover, differences in the accuracy of the values obtained in the comparison between DXA and BIA using different BIA machines has also been reported [80]. Finally, differences between the results obtained from the skinfold prediction equations compared to DXA have been shown in the literature $[81,82]$. 
Some other limitations should be mentioned, including the use of cross-sectional data (or collected by us cross-sectionally from longitudinal studies for needs related to the statistical processing of data), since this type of study design makes it difficult to explore causalities. Longitudinal data are required to further investigate the association between ST, MVPA and body composition over time [83].

Consistent with the chosen inclusion/exclusion criteria, we examined only 14 studies from the literature, and our results cannot be considered representative of the entire child and adolescent population of each country. Concerning the country of the samples, the majority of included research was from developed countries (Europe and North America) and just four studies were from developing countries (South America and Africa). Therefore, the underrepresentation of developing countries and the lack of published results from Asia has to be underlined. Although there are several studies in the literature on PA evaluated with accelerometry in Asian children and adolescents, these studies employed different accelerometers (e.g., [84,85]) and/or different cutoff points (e.g., [84-86]).

We selected only those studies that used the same type of device and cutoffs, but caution should be taken in evaluating the results obtained due to other possible variations among laboratories in procedures and methods (differences in registration period protocol, non-wear time definition, epoch length, etc.) [87]. In particular, one limitation evident in the current study is that a different number of valid days (defined as hours of monitor wear time) of accelerometer wear time was used for the final analysis. Only one study required at least six valid days of accelerometer wear time to be included in the final analysis [38], suggesting a possible PA undersampling [88]. A valid day was defined as a minimum of $6 \mathrm{~h} \mathrm{[26]} \mathrm{to} \mathrm{a} \mathrm{maximum} \mathrm{of} 17 \mathrm{~h} \mathrm{[41]} \mathrm{of} \mathrm{wearing} \mathrm{time} \mathrm{per} \mathrm{day,} \mathrm{depending} \mathrm{on} \mathrm{the} \mathrm{study.}$

Finally, concerning the size of the samples, it should be noted that it was not homogenous within the selected studies. The study with the smallest sample was reported by Hallal et al. [38] (9 males and 16 females). Meanwhile, the study with the largest sample was published by Herrmann et al. [39] (1409 males and 1544 females). To avoid biases in the statistical analysis we weighted our results for the number of the subjects of each study. In addition, we could not dispose of data regarding the first two age classes (6-7) in the chosen age range (6-15).

\section{Conclusions}

This scoping review first summarized the extent and nature of the research and identified gaps in the existing literature in order to subsequently identify key research priorities in PA and body composition. Consistent methods of measurement and analysis for both PA and body composition are required to allow comparison between literature studies and to achieve definitive conclusions. Despite some limitations, the data presented here support the suggestion that lower volumes of MVPA and higher volumes of ST are associated with increases in FM, which is detrimental to health and necessitates identification of appropriate interventions to reduce sedentary time and inactivity.

This scoping review confirmed that the adoption of standardized methods and analysis protocols for the assessment of PA and body composition remains an important concern for this area in order to improve comparability between studies. In order to obtain a realistic picture of the situation for children and adolescents, we also suggest reporting the data separately by sex. Only in this way will a better understanding of the associations between sedentary behaviour and daily PA at different levels of intensity be achieved in childhood and adolescence to successfully prevent early fat accumulation in children and lower the risk of adult obesity and its consequent comorbidities. Therefore, all children and adolescents, especially girls (who are more inactive and have greater adiposity in comparison to boys), should be encouraged to partake in PA, because of obesity seems to be due mainly to decreased PA and increased sedentary behaviour.

Author Contributions: Conceptualization, E.G.-R. and L.Z.; methodology, E.G.-R. and N.R.; formal analysis, L.Z. and N.R.; investigation, E.G.-R. and N.R.; data curation, N.R., L.Z. and S.T.; writingoriginal draft preparation, E.G.-R., L.Z. and N.R.; writing-review and editing, E.G.-R., L.Z., N.R. 
and S.T.; supervision, E.G.-R.; project administration, E.G.-R. All authors have read and agreed to the published version of the manuscript.

Funding: This research received no external funding.

Institutional Review Board Statement: Not applicable.

Informed Consent Statement: Not applicable.

Data Availability Statement: Data is contained within the article.

Conflicts of Interest: The authors declare no conflict of interest.

\section{References}

1. Ha, A.S.; Ng, J.Y.Y.; Lonsdale, C.; Lubans, D.R.; Ng, F.F. Promoting physical activity in children through family-based intervention: Protocol of the "Active 1+FUN" randomized controlled trial. BMC Public Health 2019, 19, 218. [CrossRef]

2. Zaccagni, L.; Rinaldo, N.; Bramanti, B.; Gualdi-Russo, E. Relation between lifestyle behaviors and body composition patterns among healthy young Italians: A cross-sectional study. J. Sports Med. Phys. Fit. 2018, 58, 1652-1656. [CrossRef]

3. NCD Risk Factor Collaboration (NCD-RisC). Worldwide trends in body-mass index, underweight, overweight, and obesity from 1975 to 2016: A pooled analysis of 2416 population-based measurement studies in 1289 million children, adolescents, and adults. Lancet 2017, 390, 2627-2642. [CrossRef]

4. NCD Risk Factor Collaboration (NCD-RisC). Rising rural body-mass index is the main driver of the global obesity epidemic in adults. Nature 2019, 569, 260-264. [CrossRef] [PubMed]

5. Ness, A.R.; Leary, S.D.; Mattocks, C.; Blair, S.N.; Reilly, J.J.; Wells, J.; Ingle, S.; Tilling, K.; Smith, G.D.; Riddoch, C. Objectively measured physical activity and fat mass in a large cohort of children. PLoS Med. 2007, 4, e97. [CrossRef] [PubMed]

6. Metcalf, B.; Henley, W.; Wilkin, T. Effectiveness of intervention on physical activity of children: Systematic review and metaanalysis of controlled trials with objectively measured outcomes (EarlyBird 54). BMJ 2012, 345, e5888. [CrossRef] [PubMed]

7. Harris, K.C.; Kuramoto, L.K.; Schulzer, M.; Retallack, J.E. Effect of school-based physical activity interventions on body mass index in children: A meta-analysis. CMAJ 2009, 180, 719-726. [CrossRef] [PubMed]

8. Waters, E.; de Silva-Sanigorski, A.; Hall, B.J.; Brown, T.; Campbell, K.J.; Gao, Y.; Armstrong, R.; Prosser, L.; Summerbell, C.D. Interventions for preventing obesity in children. Cochrane Database Syst. Rev. 2011, CD001871. [CrossRef] [PubMed]

9. Wilks, D.C.; Sharp, S.J.; Ekelund, U.; Thompson, S.G.; Mander, A.P.; Turner, R.M.; Jebb, S.A.; Lindroos, A.K. Objectively measured physical activity and fat mass in children: A bias-adjusted meta-analysis of prospective studies. PLoS ONE 2011, 6, e17205. [CrossRef] [PubMed]

10. Kwon, S.; Janz, K.F.; Letuchy, E.M.; Burns, T.L.; Levy, S.M. Active lifestyle in childhood and adolescence prevents obesity development in young adulthood. Obesity 2015, 23, 2462-2469. [CrossRef]

11. Katzmarzyk, P.T.; Barreira, T.V.; Broyles, S.T.; Champagne, C.M.; Chaput, J.-P.; Fogelholm, M.; Hu, G.; Johnson, W.D.; Kuriyan, R.; Kurpad, A.; et al. Physical Activity, Sedentary Time, and Obesity in an International Sample of Children. Med. Sci. Sports Exerc. 2015, 47, 2062-2069. [CrossRef] [PubMed]

12. Kelley, G.A.; Kelley, K.S.; Pate, R.R. Exercise and BMI in Overweight and Obese Children and Adolescents: A Systematic Review and Trial Sequential Meta-Analysis. BioMed Res. Int. 2015, 2015, 704539. [CrossRef] [PubMed]

13. McClung, H.L.; Ptomey, L.T.; Shook, R.P.; Aggarwal, A.; Gorczyca, A.M.; Sazonov, E.S.; Becofsky, K.; Weiss, R.; Das, S.K. Dietary Intake and Physical Activity Assessment: Current Tools, Techniques, and Technologies for Use in Adult Populations. Am. J. Prev. Med. 2018, 55, e93-e104. [CrossRef] [PubMed]

14. Treuth, M.S.; Hou, N.; Young, D.R.; Maynard, L.M. Validity and reliability of the Fels physical activity questionnaire for children. Med. Sci. Sports Exerc. 2005, 37, 488-495. [CrossRef]

15. Trost, S.G.; Loprinzi, P.D.; Moore, R.; Pfeiffer, K.A. Comparison of accelerometer cut points for predicting activity intensity in youth. Med. Sci. Sports Exerc. 2011, 43, 1360-1368. [CrossRef]

16. Duncan, S.; Stewart, T.; Bo Schneller, M.; Godbole, S.; Cain, K.; Kerr, J. Convergent validity of ActiGraph and Actical accelerometers for estimating physical activity in adults. PLoS ONE 2018, 13, e0198587. [CrossRef]

17. Wijndaele, K.; Westgate, K.; Stephens, S.K.; Blair, S.N.; Bull, F.C.; Chastin, S.F.M.; Dunstan, D.W.; Ekelund, U.; Esliger, D.W.; Freedson, P.S.; et al. Utilization and Harmonization of Adult Accelerometry Data: Review and Expert Consensus. Med. Sci. Sports Exerc. 2015, 47, 2129-2139. [CrossRef]

18. Colley, R.C.; Garriguet, D.; Janssen, I.; Craig, C.L.; Clarke, J.; Tremblay, M.S. Physical activity of Canadian children and youth: Accelerometer results from the 2007 to 2009 Canadian Health Measures Survey. Health Rep. 2011, 22, 15-23.

19. Vanhelst, J.; Béghin, L.; Duhamel, A.; Bergman, P.; Sjöström, M.; Gottrand, F. Comparison of uniaxial and triaxial accelerometry in the assessment of physical activity among adolescents under free-living conditions: The HELENA study. BMC Med. Res. Methodol. 2012, 12, 26. [CrossRef]

20. Smith, M.P.; Horsch, A.; Standl, M.; Heinrich, J.; Schulz, H. Uni- and triaxial accelerometric signals agree during daily routine, but show differences between sports. Sci. Rep. 2018, 8, 15055. [CrossRef]

21. Freedson, P.; Pober, D.; Janz, K.F. Calibration of accelerometer output for children. Med. Sci. Sports Exerc. 2005, 37, S523-S530. [CrossRef] [PubMed] 
22. Puyau, M.R.; Adolph, A.L.; Vohra, F.A.; Butte, N.F. Validation and calibration of physical activity monitors in children. Obes. Res. 2002, 10, 150-157. [CrossRef] [PubMed]

23. Treuth, M.S.; Schmitz, K.; Catellier, D.J.; McMurray, R.G.; Murray, D.M.; Almeida, M.J.; Going, S.; Norman, J.E.; Pate, R. Defining accelerometer thresholds for activity intensities in adolescent girls. Med. Sci. Sports Exerc. 2004, 36, 1259-1266. [PubMed]

24. Mattocks, C.; Leary, S.; Ness, A.; Deere, K.; Saunders, J.; Tilling, K.; Kirkby, J.; Blair, S.N.; Riddoch, C. Calibration of an accelerometer during free-living activities in children. Int. J. Pediatr. Obes. 2007, 2, 218-226. [CrossRef]

25. Evenson, K.R.; Catellier, D.J.; Gill, K.; Ondrak, K.S.; McMurray, R.G. Calibration of two objective measures of physical activity for children. J. Sports Sci. 2008, 26, 1557-1565. [CrossRef]

26. Diouf, A.; Thiam, M.; Idohou-Dossou, N.; Diongue, O.; Mégné, N.; Diallo, K.; Sembène, P.M.; Wade, S. Physical activity level and sedentary behaviors among public school children in dakar (senegal) measured by paq-c and accelerometer: Preliminary results. Int. J. Environ. Res. Public Health 2016, 13, 998. [CrossRef]

27. Malina, R.M.; Koziel, S.; Bielicki, T. Variation in subcutaneous adipose tissue distribution associated with age, sex, and maturation. Am. J. Hum. Biol. 1999, 11, 189-200. [CrossRef]

28. Kirchengast, S. Gender differences in body composition from childhood to old age: An evolutionary point of view. J. Life Sci. 2010, 2, 1-10. [CrossRef]

29. Grant, M.J.; Booth, A. A typology of reviews: An analysis of 14 review types and associated methodologies. Health Inf. Libr. J. 2009, 26, 91-108. [CrossRef]

30. Moher, D.; Liberati, A.; Tetzlaff, J.; Altman, D.G. Preferred reporting items for systematic reviews and meta-analyses: The PRISMA Statement. Open Med. 2009, 3, e123-e130.

31. Tricco, A.C.; Lillie, E.; Zarin, W.; O’Brien, K.K.; Colquhoun, H.; Levac, D.; Moher, D.; Peters, M.D.J.; Horsley, T.; Weeks, L.; et al. PRISMA Extension for Scoping Reviews (PRISMA-ScR): Checklist and Explanation. Ann. Intern. Med. 2018, 169, 467-473. [CrossRef] [PubMed]

32. Ben Jemaa, H.; Mankaï, A.; Mahjoub, F.; Kortobi, B.; Khlifi, S.; Draoui, J.; Minaoui, R.; Karmous, I.; Ben Hmad, H.; Ben Slama, F.; et al. Physical Activity Level Assessed by Accelerometer and PAQ-C in Tunisian Children. Ann. Nutr. Metab. 2018, 73, 234-240. [CrossRef] [PubMed]

33. Benítez-Porres, J.; Alvero-Cruz, J.R.; Sardinha, L.B.; López-Fernández, I.; Carnero, E.A. Valores de corte para clasificar niños y adolescentes activos utilizando el cuestionario de actividad física: PAQ-C y PAQ-A. Nutr. Hosp. 2016, 33, 1036-1044. [CrossRef]

34. Bernhardsen, G.P.; Stensrud, T.; Nystad, W.; Dalene, K.E.; Kolle, E.; Ekelund, U. Early life risk factors for childhood obesity-Does physical activity modify the associations? The MoBa cohort study. Scand. J. Med. Sci. Sports 2019, 29, 1636-1646. [CrossRef] [PubMed]

35. Chaput, J.P.; Lambert, M.; Mathieu, M.E.; Tremblay, M.S.; O’Loughlin, J.; Tremblay, A. Physical activity vs. sedentary time: Independent associations with adiposity in children. Pediatr. Obes. 2012, 7, 251-258. [CrossRef] [PubMed]

36. de Moraes Ferrari, G.L.; Oliveira, L.C.; Araujo, T.L.; Matsudo, V.; Barreira, T.V.; Tudor-Locke, C.; Katzmarzyk, P. Moderate-toVigorous Physical Activity and Sedentary Behavior: Independent Associations With Body Composition Variables in Brazilian Children. Pediatr. Exerc. Sci. 2015, 27, 380-389. [CrossRef]

37. Gába, A.; Mitáš, J.; Jakubec, L. Associations between accelerometer-measured physical activity and body fatness in school-aged children. Environ. Health Prev. Med. 2017, 22, 43. [CrossRef]

38. Hallal, P.C.; Reichert, F.F.; Clark, V.L.; Cordeira, K.L.; Menezes, A.M.B.; Eaton, S.; Ekelund, U.; Wells, J.C. Energy expenditure compared to physical activity measured by accelerometry and self-report in adolescents: A validation study. PLoS ONE 2013, 8, e77036. [CrossRef]

39. Herrmann, D.; Buck, C.; Sioen, I.; Kouride, Y.; Marild, S.; Molnár, D.; Mouratidou, T.; Pitsiladis, Y.; Russo, P.; Veidebaum, T.; et al. Impact of physical activity, sedentary behaviour and muscle strength on bone stiffness in 2-10-year-old children-cross-sectional results from the IDEFICS study. Int. J. Behav. Nutr. Phys. Act. 2015, 12, 112. [CrossRef]

40. Janz, K.F.; Boros, P.; Letuchy, E.M.; Kwon, S.; Burns, T.L.; Levy, S.M. Physical Activity, Not Sedentary Time, Predicts Dual-Energy X-ray Absorptiometry-measured Adiposity Age 5 to 19 Years. Med. Sci. Sports Exerc. 2017, 49, 2071-2077. [CrossRef]

41. Joensuu, L.; Syväoja, H.; Kallio, J.; Kulmala, J.; Kujala, U.M.; Tammelin, T.H. Objectively measured physical activity, body composition and physical fitness: Cross-sectional associations in 9- to 15-year-old children. Eur. J. Sport Sci. 2018, 18, 882-892. [CrossRef] [PubMed]

42. McCormack, L.; Meendering, J.; Specker, B.; Binkley, T. Associations Between Sedentary Time, Physical Activity, and Dual-Energy X-ray Absorptiometry Measures of Total Body, Android, and Gynoid Fat Mass in Children. J. Clin. Densitom. 2016, 19, 368-374. [CrossRef] [PubMed]

43. Santos-Magalhaes, A.F.; Aires, L.; Martins, C.; Silva, G.; Teixeira, A.M.; Mota, J.; Rama, L. Heart rate variability, adiposity, and physical activity in prepubescent children. Clin. Auton. Res. 2015, 25, 169-178. [CrossRef]

44. Sardinha, L.B.; Magalhães, J.P.; Santos, D.A.; Júdice, P.B. Sedentary patterns, physical activity, and cardiorespiratory fitness in association to glycemic control in type 2 diabetes patients. Front. Physiol. 2017, 8, 262. [CrossRef]

45. Amo-Setién, F.J.; Leal-Costa, C.; Abajas-Bustillo, R.; González-Lamuño, D.; Redondo-Figuero, C. Factors associated with grip strength among adolescents: An observational study. J. Hand Ther. 2020, 33, 96-102. [CrossRef] [PubMed]

46. Ainsworth, B.E.; Caspersen, C.J.; Matthews, C.E.; Mâsse, L.C.; Baranowski, T.; Zhu, W. Recommendations to improve the accuracy of estimates of physical activity derived from self report. J. Phys. Act. Health 2012, 9 (Suppl. 1), S76-S84. [CrossRef] 
47. Spruijt-Metz, D.; Wen, C.K.F.; Bell, B.M.; Intille, S.; Huang, J.S.; Baranowski, T. Advances and Controversies in Diet and Physical Activity Measurement in Youth. Am. J. Prev. Med. 2018, 55, e81-e91. [CrossRef]

48. Cain, K.L.; Sallis, J.F.; Conway, T.L.; Van Dyck, D.; Calhoon, L. Using accelerometers in youth physical activity studies: A review of methods. J. Phys. Act. Health 2013, 10, 437-450. [CrossRef]

49. Troiano, R.P.; Berrigan, D.; Dodd, K.W.; Mâsse, L.C.; Tilert, T.; McDowell, M. Physical activity in the United States measured by accelerometer. Med. Sci. Sports Exerc. 2008, 40, 181-188. [CrossRef]

50. Ellis, K.; Kerr, J.; Godbole, S.; Staudenmayer, J.; Lanckriet, G. Hip and Wrist Accelerometer Algorithms for Free-Living Behavior Classification. Med. Sci. Sports Exerc. 2016, 48, 933-940. [CrossRef]

51. Aadland, E.; Kvalheim, O.M.; Anderssen, S.A.; Resaland, G.K.; Andersen, L.B. The multivariate physical activity signature associated with metabolic health in children. Int. J. Behav. Nutr. Phys. Act. 2018, 15, 77. [CrossRef] [PubMed]

52. Robusto, K.M.; Trost, S.G. Comparison of three generations of ActiGraph ${ }^{\mathrm{TM}}$ activity monitors in children and adolescents. J. Sports Sci. 2012, 30, 1429-1435. [CrossRef] [PubMed]

53. Kozey, S.L.; Staudenmayer, J.W.; Troiano, R.P.; Freedson, P.S. Comparison of the ActiGraph 7164 and the ActiGraph GT1M during self-paced locomotion. Med. Sci. Sports Exerc. 2010, 42, 971-976. [CrossRef] [PubMed]

54. John, D.; Tyo, B.; Bassett, D.R. Comparison of four ActiGraph accelerometers during walking and running. Med. Sci. Sports Exerc. 2010, 42, 368-374. [CrossRef] [PubMed]

55. Grydeland, M.; Hansen, B.H.; Ried-Larsen, M.; Kolle, E.; Anderssen, S.A. Comparison of three generations of ActiGraph activity monitors under free-living conditions: Do they provide comparable assessments of overall physical activity in 9-year old children? BMC Sports Sci. Med. Rehabil. 2014, 6, 26. [CrossRef] [PubMed]

56. Robertson, W.; Stewart-Brown, S.; Wilcock, E.; Oldfield, M.; Thorogood, M. Utility of accelerometers to measure physical activity in children attending an obesity treatment intervention. J. Obes. 2011, 2011. [CrossRef]

57. Trost, S.G.; Mciver, K.L.; Pate, R.R. Conducting accelerometer-based activity assessments in field-based research. Med. Sci. Sports Exerc. 2005, 37, S531-S543. [CrossRef]

58. Aadland, E.; Ylvisåker, E. Reliability of the Actigraph GT3X+ Accelerometer in Adults under Free-Living Conditions. PLoS ONE 2015, 10, e0134606. [CrossRef]

59. Trost, S.G.; Ward, D.S.; Moorehead, S.M.; Watson, P.D.; Riner, W.; Burke, J.R. Validity of the computer science and applications (CSA) activity monitor in children. Med. Sci. Sports Exerc. 1998, 30, 629-633. [CrossRef]

60. O'Neil, M.E.; Fragala-Pinkham, M.A.; Forman, J.L.; Trost, S.G. Measuring reliability and validity of the ActiGraph GT3X accelerometer for children with cerebral palsy: A feasibility study. J. Pediatr. Rehabil. Med. 2014, 7, 233-240. [CrossRef]

61. Brocklebank, L.A.; Falconer, C.L.; Page, A.S.; Perry, R.; Cooper, A.R. Accelerometer-measured sedentary time and cardiometabolic biomarkers: A systematic review. Prev. Med. 2015, 76, 92-102. [CrossRef] [PubMed]

62. Rey Lopez, J.P.; Sabag, A.; Martinez Juan, M.; Rezende, L.F.M.; Pastor-Valero, M. Do vigorous-intensity and moderate-intensity physical activities reduce mortality to the same extent? A systematic review and meta-analysis. BMJ Open Sport Exerc. Med. 2020, 6, e000775. [CrossRef] [PubMed]

63. Malina, R.M.; Eisenmann, J.C.; Cumming, S.P.; Ribeiro, B.; Aroso, J. Maturity-associated variation in the growth and functional capacities of youth football (soccer) players 13-15 years. Eur. J. Appl. Physiol. 2004, 91, 555-562. [CrossRef]

64. Weber, D.R.; Leonard, M.B.; Zemel, B.S. Body composition analysis in the pediatric population. Pediatr. Endocrinol. Rev. 2012, 10, 130-139. [PubMed]

65. Kindblom, J.M.; Lorentzon, M.; Hellqvist, A.; Lönn, L.; Brandberg, J.; Nilsson, S.; Norjavaara, E.; Ohlsson, C. BMI changes during childhood and adolescence as predictors of amount of adult subcutaneous and visceral adipose tissue in men: The GOOD Study. Diabetes 2009, 58, 867-874. [CrossRef] [PubMed]

66. Strong, W.B.; Malina, R.M.; Blimkie, C.J.R.; Daniels, S.R.; Dishman, R.K.; Gutin, B.; Hergenroeder, A.C.; Must, A.; Nixon, P.A.; Pivarnik, J.M.; et al. Evidence based physical activity for school-age youth. J. Pediatr. 2005, 146, 732-737. [CrossRef]

67. Tremblay, M.S.; LeBlanc, A.G.; Kho, M.E.; Saunders, T.J.; Larouche, R.; Colley, R.C.; Goldfield, G.; Connor Gorber, S. Systematic review of sedentary behaviour and health indicators in school-aged children and youth. Int. J. Behav. Nutr. Phys. Act. 2011, 8, 98. [CrossRef]

68. Prentice-Dunn, H.; Prentice-Dunn, S. Physical activity, sedentary behavior, and childhood obesity: A review of cross-sectional studies. Psychol. Health Med. 2012, 17, 255-273. [CrossRef]

69. Gualdi-Russo, E.; Zaccagni, L.; Manzon, V.S.; Masotti, S.; Rinaldo, N.; Khyatti, M. Obesity and physical activity in children of immigrants. Eur. J. Public Health 2014, 24, 40-46. [CrossRef]

70. Draper, C.E.; Tomaz, S.A.; Stone, M.; Hinkley, T.; Jones, R.A.; Louw, J.; Twine, R.; Kahn, K.; Norris, S.A. Developing Intervention Strategies to Optimise Body Composition in Early Childhood in South Africa. BioMed Res. Int. 2017, 2017, 5283457. [CrossRef]

71. de Araújo, L.G.M.; Turi, B.C.; Locci, B.; Mesquita, C.A.A.; Fonsati, N.B.; Monteiro, H.L. Patterns of Physical Activity and Screen Time Among Brazilian Children. J. Phys. Act. Health 2018, 15, 457-461. [CrossRef] [PubMed]

72. Gerber, M.; Müller, I.; Walter, C.; du Randt, R.; Adams, L.; Gall, S.; Joubert, N.; Nqweniso, S.; Smith, D.; Steinmann, P.; et al. Physical activity and dual disease burden among South African primary schoolchildren from disadvantaged neighbourhoods. Prev. Med. 2018, 112, 104-110. [CrossRef] 
73. Ferrari, G.L.; Kovalskys, I.; Fisberg, M.; Gómez, G.; Rigotti, A.; Sanabria, L.Y.C.; García, M.C.Y.; Torres, R.G.P.; Herrera-Cuenca, M.; Zimberg, I.Z.; et al. Comparison of self-report versus accelerometer-Measured physical activity and sedentary behaviors and their association with body composition in Latin American countries. PLoS ONE 2020, 15, e0232420. [CrossRef] [PubMed]

74. Guthold, R.; Stevens, G.A.; Riley, L.M.; Bull, F.C. Global trends in insufficient physical activity among adolescents: A pooled analysis of 298 population-based surveys with 1.6 million participants. Lancet Child. Adolesc. Health 2020, 4, 23-35. [CrossRef]

75. Christakoudi, S.; Tsilidis, K.K.; Muller, D.C.; Freisling, H.; Weiderpass, E.; Overvad, K.; Söderberg, S.; Häggström, C.; Pischon, T.; Dahm, C.C.; et al. A Body Shape Index (ABSI) achieves better mortality risk stratification than alternative indices of abdominal obesity: Results from a large European cohort. Sci. Rep. 2020, 10, 14541. [CrossRef]

76. Giudici, K.V.; Martini, L.A. Comparison between body mass index and a body shape index with adiponectin/leptin ratio and markers of glucose metabolism among adolescents. Ann. Hum. Biol. 2017, 44, 489-494. [CrossRef]

77. Freedman, D.S.; Sherry, B. The validity of BMI as an indicator of body fatness and risk among children. Pediatrics 2009, 124 (Suppl. 1), S23-S34. [CrossRef]

78. Achamrah, N.; Colange, G.; Delay, J.; Rimbert, A.; Folope, V.; Petit, A.; Grigioni, S.; Déchelotte, P.; Coëffier, M. Comparison of body composition assessment by DXA and BIA according to the body mass index: A retrospective study on 3655 measures. PLoS ONE 2018, 13, e0200465. [CrossRef]

79. Lee, S.Y.; Ahn, S.; Kim, Y.J.; Ji, M.J.; Kim, K.M.; Choi, S.H.; Jang, H.C.; Lim, S. Comparison between Dual-Energy X-ray Absorptiometry and Bioelectrical Impedance Analyses for Accuracy in Measuring Whole Body Muscle Mass and Appendicular Skeletal Muscle Mass. Nutrients 2018, 10, 738. [CrossRef]

80. Alkahtani, S.A. A cross-sectional study on sarcopenia using different methods: Reference values for healthy Saudi young men. BMC Musculoskelet. Disord. 2017, 18, 119. [CrossRef]

81. Duz, S.; Kocak, M.; Korkusuz, F. Evaluation of body composition using three different methods compared to dual-energy X-ray absorptiometry. Eur. J. Sport Sci. 2009, 9, 181-190. [CrossRef]

82. Benito, P.J.; Gómez-Candela, C.; Cabañas, M.D.; Szendrei, B.; Castro, E.A. Comparison between different methods for measuring body fat after a weight loss program. Rev. Bras. Med. Esporte 2019, 25, 474-479. [CrossRef]

83. Must, A.; Tybor, D.J. Physical activity and sedentary behavior: A review of longitudinal studies of weight and adiposity in youth. Int. J. Obes. 2005, 29 (Suppl. 2), S84-S96. [CrossRef]

84. Hong, H.-R.; Ha, C.-D.; Kong, J.-Y.; Lee, S.-H.; Song, M.-G.; Kang, H.-S. Roles of physical activity and cardiorespiratory fitness on sex difference in insulin resistance in late elementary years. J. Exerc. Nutr. Biochem. 2014, 18, 361-369. [CrossRef] [PubMed]

85. Ishikawa-Takata, K.; Kaneko, K.; Koizumi, K.; Ito, C. Comparison of physical activity energy expenditure in Japanese adolescents assessed by EW4800P triaxial accelerometry and the doubly labelled water method. Br. J. Nutr. 2013, 110, 1347-1355. [CrossRef] [PubMed]

86. Lv, Y.; Cai, L.; Gui, Z.; Zeng, X.; Tan, M.; Wan, N.; Lai, L.; Lu, S.; Tan, W.; Chen, Y. Effects of physical activity and sedentary behaviour on cardiometabolic risk factors and cognitive function in children: Protocol for a cohort study. BMJ Open 2019, 9, e030322. [CrossRef] [PubMed]

87. Migueles, J.H.; Cadenas-Sanchez, C.; Ekelund, U.; Delisle Nyström, C.; Mora-Gonzalez, J.; Löf, M.; Labayen, I.; Ruiz, J.R.; Ortega, F.B. Accelerometer Data Collection and Processing Criteria to Assess Physical Activity and Other Outcomes: A Systematic Review and Practical Considerations. Sports Med. 2017, 47, 1821-1845. [CrossRef]

88. Matthews, C.E.; Ainsworth, B.E.; Thompson, R.W.; Bassett, D.R.J. Sources of variance in daily physical activity levels as measured by an accelerometer. Med. Sci. Sports Exerc. 2002, 34, 1376-1381. [CrossRef] 